\title{
Localization and activity of rDNA genes in tiger beetles (Coleoptera: Cicindelinae)
}

\author{
JOSÉ GALIÁN*, JOSÉ SERRANO, PILAR DE LA RÚA, EDUARD PETITPIERRE† \& \\ CARLOS JUAN $\ddagger$ \\ Departamento de Biologia Animal, Facultad de Veterinaria, Universidad de Murcia, 30071 Murcia, Spain, †Laboratori de \\ Genètica, Departament de Biologia Ambiental, Universitat de les Illes Balears, 07071 Palma de Mallorca, Spain and \\ $\ddagger$ School of Biological Sciences, University of East Anglia, Norwich NR4 7TJ, UK.
}

\begin{abstract}
Silver staining of male meiotic nuclei of six species of the tiger beetle genus Cicindela (tribe Cicindelini), with multiple sex chromosomes, reveals the presence of active nucleolar organizing regions (NORs) in the sex vesicle. In one species, Cicindela melancholica, fluorescence in situ hybridization (FISH) with a ribosomal probe showed that rDNA genes are in one of the three X chromosomes and in the Y chromosome. Silver staining and FISH show that the related species Cicindela paludosa with a male XO system, has NORs located in one pair of autosomes. In Megacephala euphratica (tribe Megacephalini) these techniques indicate that NORs are located in three autosomal pairs but not in the single $X$ chromosome of males. In all these species the nucleolus can be seen from the onset of meiosis to the end of the diffuse stage; it disappears from diplotene to the end of meiosis and appears again during the spermatid stage. From these results it is concluded that: (i) the nucleolus does not seem to play a major role in the pairing and association of the multiple sex chromosomes during first meiotic prophase and metaphase; (ii) the occurrence of NORs in the heterosomes of species having multiple sex chromosomes is thought to be an ancestral condition for the genus Cicindela; and (iii) changes of location of NORs from the heterosomes to the autosomes have occurred within species of this genus, at least in species showing extensive karyotypic repatterning.
\end{abstract}

Keywords: Caraboidea, Cicindelinae, Coleoptera, FISH, NORs, rDNA.

\section{Introduction}

Little attention has been paid to the localization of nucleolar organizers (NORs) in Adephagan beetles, in contrast to the studies concerning species of the large suborder Polyphaga (Drets et al., 1983; Postiglioni \& Brum-Zorrilla, 1988; Virkki et al., 1990, 1991; Juan et al., 1993). Weber (1971) reported the occurrence of NORs in the largest autosomal pair of Carabus auronitens and $C$. granulatus, using light and electron microscopy. Secondary constrictions indicating possible NORs have also been reported in a number of other carabid species (Serrano, 1986; Serrano et al., 1986; Galián et al., 1990), but no specific methodology has been worked out for analysing the nucleolus.

Despite this, there is much debate about the role of the nucleolus in the association of the typical Xyp sex chromosomes of the suborder Polyphaga (see for example Juan et al., 1993). The sex-bivalent Xyp has a parachute-like shape where the $\mathrm{X}$ chromosome repre-

*Correspondence. sents the parachute proper and the $y$ chromosome the load, which is connected to the $\mathrm{X}$ by two tenuous threads (Smith \& Virkki, 1978). Since the early statements of John \& Lewis (1960) that the nucleolus is necessary for the Xyp to achieve regular co-orientation during metaphase I, there have been other results which show that the sex bivalent does not have a typical nucleolus, although an argyrophilous substance is developed between sex chromosomes that may carry out the functions postulated by John \& Lewis (Postiglioni \& Brum-Zorrilla, 1988; Virkki et al., 1990, 1991).

Tiger beetles are carabids belonging to the subfamily Cicindelinae which are characterized by the presence of multiple sex chromosomes and form a nonchiasmatic multivalent (Giers, 1977) so they are suitable for studying the localization of NORs and the role of the nucleolus during meiosis. The generalized karyotype consists of nine to 12 autosomes plus $\mathrm{X}_{\mathrm{n}} \mathrm{Y}$, where $\mathrm{n}$ varies between 2 and 4 (Serrano, 1980; Serrano et al., 1986; Serrano \& Collares-Pereira, 1989, 1992; Galián et al., 1990). Only two species show an X0 sex chromo- 
some mechanism, probably of unlike origin: Megacephala euphratica (tribe Megacephalini) and Cicindela paludosa (tribe Cicindelini; Serrano et al., 1986).

The introduction of fluorescence in situ hybridization (FISH) in many animal and plant species including beetles, has allowed the localization and mapping of specific DNA sequences on chromosomes as for example rDNA genes (Juan et al., 1993, and additional references therein). FISH differs from silver staining in that it reveals the actual number of chromosomes carrying NORs whereas silver staining indicates which of these are active in a particular stage of the cell cycle. Moreover, silver staining may indicate the presence of a nucleolar-like substance within chromosomes lacking a NOR. Thus, the Polyphagan beetle Misolampus goudoti (family Tenebrionidae) does not have NORs in the Xyp chromosomes in contrast to the related species Tenebrio molitor, but in both species the sexual bivalent is heavily silver-stained up to anaphase I (Juan et al., 1993).

In this paper we applied silver staining and fluorescence in situ hybridization with a ribosomal probe to tiger beetles' germ cells to show the chromosomal localization of rDNA genes, their relationship to pairing of multiple sex chromosomes and their phylogenetic significance.

\section{Materials and methods}

\section{Material}

The species sampled in the study were collected in the localities of southeastern Spain listed in Table 1.

\section{Chromosome preparations}

Male gonads from adult beetles were used to obtain mitotic or meiotic chromosomes and nuclei. Gonads were dissected from beetles anaesthetized by ethyl acetate. A $0.04 \mathrm{~m}$ sodium acetate solution plus 0.05 per cent colchicine solution was injected $1 \mathrm{~h}$ prior to dissection. Gonads were fixed in fresh ethanol-acetatic acid solution ( $3: 1$ ) for $1 \mathrm{~h}$. Routine staining was carried out with acetic orcein for $10 \mathrm{~min}$ and squashing. For silver staining small sections of the gonads were squashed in 45 per cent acetic acid and the coverslip removed after freezing in liquid nitrogen. Slides were dried in a $60^{\circ} \mathrm{C}$ hot plate. For in situ hybridization small sections of the gonads were placed in eppendorff tubes with $20 \mu \mathrm{L}$ of 60 per cent acetic acid, to break up the tissue giving a cell suspension. Drops of this suspension $(5 \mu \mathrm{L})$ were placed on preheated slides and dried on a $60^{\circ} \mathrm{C}$ hot plate.

\section{Silver staining}

A solution of 20 per cent $\mathrm{AgNO}_{3}$ in distilled water previously adjusted to $\mathrm{pH} 3.0$ with formic acid was used. The solution was kept in the dark for $15 \mathrm{~min}$ with occasional shaking and was thereafter centrifuged at $13000 \mathrm{~g}$ for $5 \mathrm{~min}$ to separate the silver previously precipitated. A $100 \mu \mathrm{L}$ aliquot of the supernatant was placed on the slides and incubated at $70^{\circ} \mathrm{C}$ during 5-15 min in a humid chamber. The slides were rinsed thoroughly in distilled water, counterstained with 2 per cent Giemsa in phosphate buffer pH 6.8, washed, airdried and mounted in Eukitt.

Table 1 Haploid chromosome numbers and collection sites of the eight species of tiger beetles from southeastern Spain

\begin{tabular}{lll}
\hline Species & \multicolumn{1}{c}{$n$} & Localities \\
\hline $\begin{array}{l}\text { Tribe Megacephalini } \\
\text { Megacephala euphratica }\end{array}$ & $15+\mathrm{X}$ & La Azohía (Murcia) \\
$\begin{array}{l}\text { Tribe Cicindelini } \\
\text { Cicindela campestris }\end{array}$ & $9+\mathrm{XXXY}$ & Balneario de Tus (Albacete) \\
C. maura & $9+\mathrm{XXXY}$ & Laguna del Hondo (Alicante) \\
C. deserticoloides & $9+\mathrm{XXXY}$ & San Isidro de Albatera (Alicante) \\
C. litorea & $9+\mathrm{XXXY}$ & Salinas del Rassal (Murcia) \\
C. melancholica & $9+\mathrm{XXXY}$ & El Algar (Murcia) \\
C. flexuosa & $9+\mathrm{XXXY}$ & Salinas de San Pedro (Murcia) \\
C. paludosa & $7+\mathrm{X}$ & Hellín(Albacete) \\
\hline
\end{tabular}




\section{DNA probe}

The ribosomal probe used was pDm238 (Roiha et al., $1981)$ cloned in pBR322. It contains the $18 \mathrm{~S}, 5.8 \mathrm{~S}$, $28 \mathrm{~S}$ genes, plus intergenic spacers of Drosophila melanogaster.

\section{In situ hybridization}

Methods for pretreatment of slide preparations, in situ hybridization and probe detection followed the procedure described by Juan et al. (1993) with minor modifications. Chromosome spreads were pretreated with DNase-free RNase in $2 \times \mathrm{SSC}$ for $1 \mathrm{~h}$ at $37^{\circ} \mathrm{C}$, followed by treatment with 0.005 per cent pepsin in 10 $\mathrm{mm} \mathrm{HCl}$ for $10 \mathrm{~min}$, dehydration in a graded ethanol series, and air drying. The probe was labelled with biotin-16-dUTP by nick translation. The hybridization mixture contained 50 per cent formamide, $0.1 \mu \mathrm{g} / \mu \mathrm{L}$ denatured salmon sperm DNA, $0.1 \mu \mathrm{g} / \mu \mathrm{L}$ yeast RNA and $4 \mathrm{ng} / \mu \mathrm{L}$ of labelled probe. A $5 \mu \mathrm{L}$ aliquot of this mixture was placed on the slide and covered with a $20 \times 20 \mathrm{~mm}$ coverslip. Denaturation of the probe and chromosomes was performed at the same time on a $80^{\circ} \mathrm{C}$ hot plate for $3 \mathrm{~min}$ and they were then transferred to a humid chamber at $37^{\circ} \mathrm{C}$ for hybridization overnight. After hybridization coverslips were carefully removed and the slides were then given a stringent wash three times for 5 min each in 50 per cent formamide, $2 \times \mathrm{SSC}$ at $37^{\circ} \mathrm{C}$. Sites of probe hybridization were detected with avidin-FITC (fluorescein). The signal was amplified twice using goat anti-avidin-biotin. Slides were counterstained with propidium iodide and mounted with antifade solution to reduce fade of fluorescence. Slides were examined with a Zeiss Axiophot photomicroscope and photographed with Kodak Ektachrome.

\section{Results}

\section{Conventional staining}

The male diploid chromosome number of Cicindela campestris, $C$. maura, $C$. deserticoloides, $C$. litorea, $C$. melancholica and $C$. flexuosa is $2 n=22$, with nine pairs of autosomes and four heterosomes, $n=9+\mathrm{XXXY}$ (Table 1, Fig. 1). Autosomal bivalents form chiasmata and show a regular meiosis. The multiple sex chromosomes form a heteropycnotic condensed body or 'sex-vesicle' at early zygotene (Fig. 1a), which is visible until late pachytene. Nuclear volume increases greatly during a diffuse stage that follows pachytene at which stage the chromatin decondenses (Fig. 1b). The sex vesicle evolves into individ- ualized chromosomes showing a bouquet disposition (Fig. 1c). Thereafter, from diplotene to metaphase I, the sex chromosomes show only terminal connections which are probably of a nonchiasmatic nature (Fig. 1d).

The congeneric species Cicindela paludosa has a diploid chromosome number $2 n=15(n=7+\mathrm{X})$ and an X0 sex chromosome system (Fig. 1e). Megacephala euphratica has the highest chromosome number so far known in tiger beetles, $2 n=31$, and also shows a single $\mathrm{X}$ in males (Fig. 1f).

\section{Silver staining of NORs}

Silver staining in the six species found to have multiple sex chromosomes shows the same common pattern. Two nucleolar precipitates are seen in interphase nuclei. These come together from leptotene to late pachytene and are associated to the sex vesicle (Fig. 2a, $\mathrm{b}, \mathrm{d})$. In the diffuse stage after pachytene the two precipitates are seen separated (Fig. 2c), and are joined again at early diakinesis. As diakinesis progresses the nucleolar precipitates disappear and reappear again in spermatid nuclei, where only one silver dot per nucleus is present (Fig. 2d inset).

Prophase I nuclei in $C$. paludosa show two silver dots from leptotene to zygotene (Fig. 2e right) that become fused in pachytene (Fig. 2e left) and during the diffuse stage (Fig. 2f). These dots disappear at diakinesis. No nucleolar precipitates are observed from metaphase I to anaphase II, but thereafter every spermatid nucleus shows one nucleolar precipitate. In ovariole cells of this species two precipitates are observed at interphase (not shown) as in male diffuse nuclei.

Early prophase I nuclei in $M$. euphratica show from one to four silver precipitates (Fig. $2 \mathrm{~g}$ ) that develop into four areas of silver dots during the diffuse stage (Fig. 2h). In most spermatid nuclei only one nucleolus was formed since only one dot per cell was visible.

\section{In situ hybridization with ribosomal probe}

FISH with the ribosomal probe pDm238 was performed to test for the presence of ribosomal genes detected as active with silver staining. It was performed in one species with multiple sex chromosomes, Cicindela melancholica, and in two species with an X0 sex chromosome mechanism, C. paludosa and Megacephala euphratica. Hybridization of spermatogonial mitosis of $C$. melancholica showed the presence of ribosomal genes in two nonhomologous chromosomes, one in the distal part of the $\mathrm{Y}$ chromosome and the other in an interstitial region of one of the $\mathrm{X}$ chromosomes (Fig. 3a). The intensity of fluorescence differs slightly between these two chromosomes. The two 

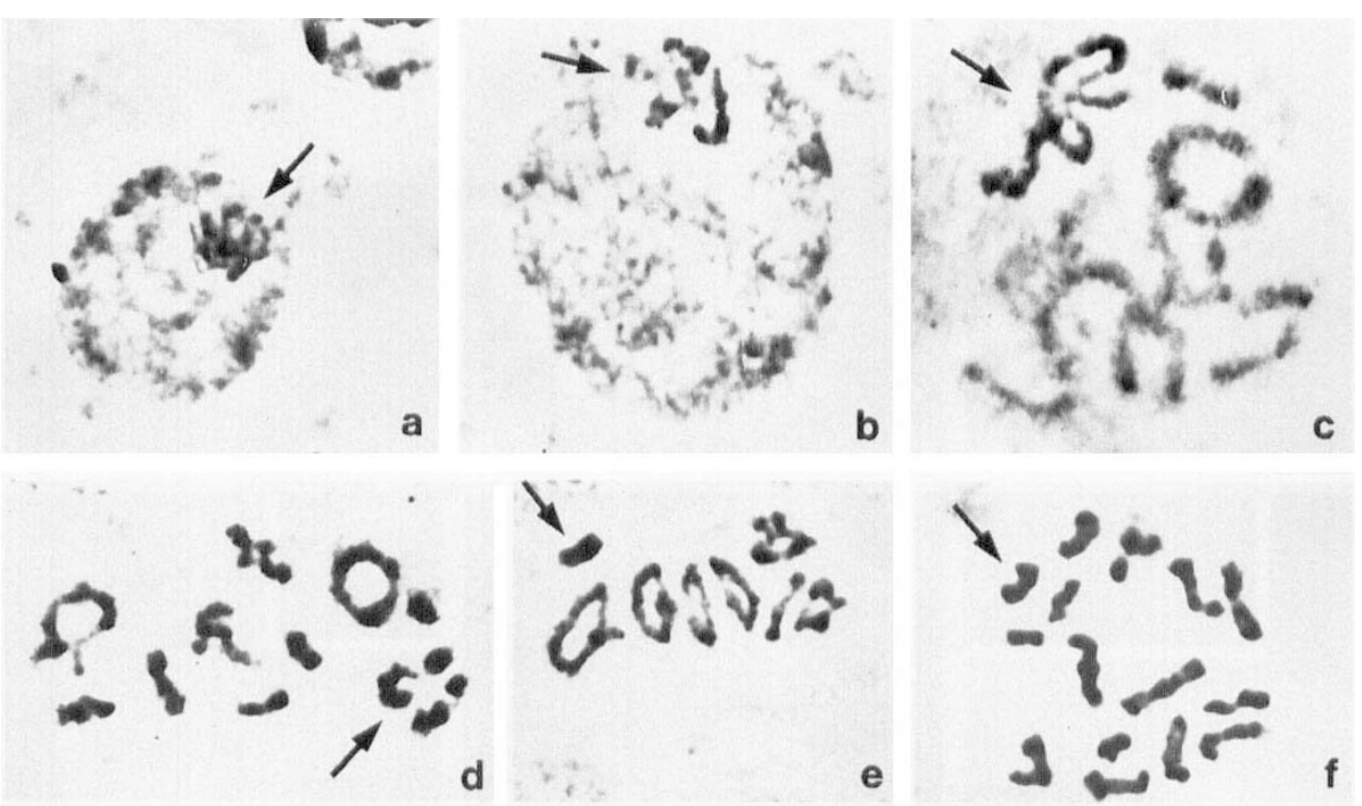

Fig. 1 Meiotic nuclei of tiger beetle species after conventional orcein staining. (a) Cicindela melancholica, zygotene. (b) $C$. deserticoloides, diffuse stage. (c) C. litorea, early diplotene. (d) C. litorea, diakinesis. (e) C. paludosa, diakinesis. (f) Megacephala euphratica, metaphase I. Arrows show the multiple sex chromosomes from (a) to (d) and the sex univalent in (e) and (f). All $\times 2000$.
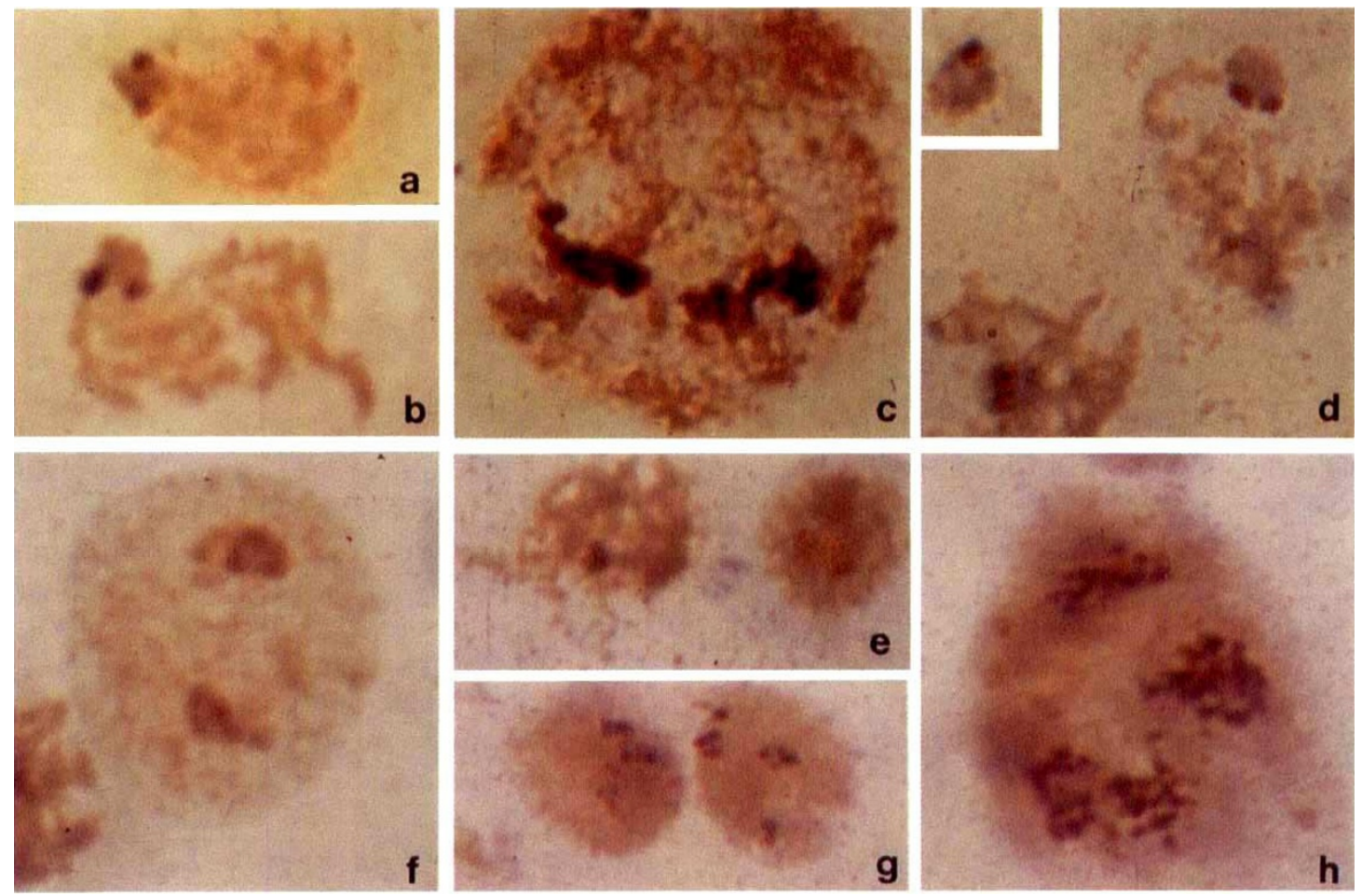

Fig. 2 Silver staining of tiger beetle meiotic nuclei. (a) Cicindela deserticoloides, pachytene. (b) C. flexuosa, late zygotene. (c) C. melancholica, diffuse stage. (d) C. melancholica, pachytene; inset: spermatid nucleus. (e) C. paludosa, zygotene (right) and pachytene (left). (f) C. paludosa, diffuse stage. (g) Megacephala euphratica, leptotene. (h) Megacephala euphratica, diffuse stage. All $\times 2000$. 

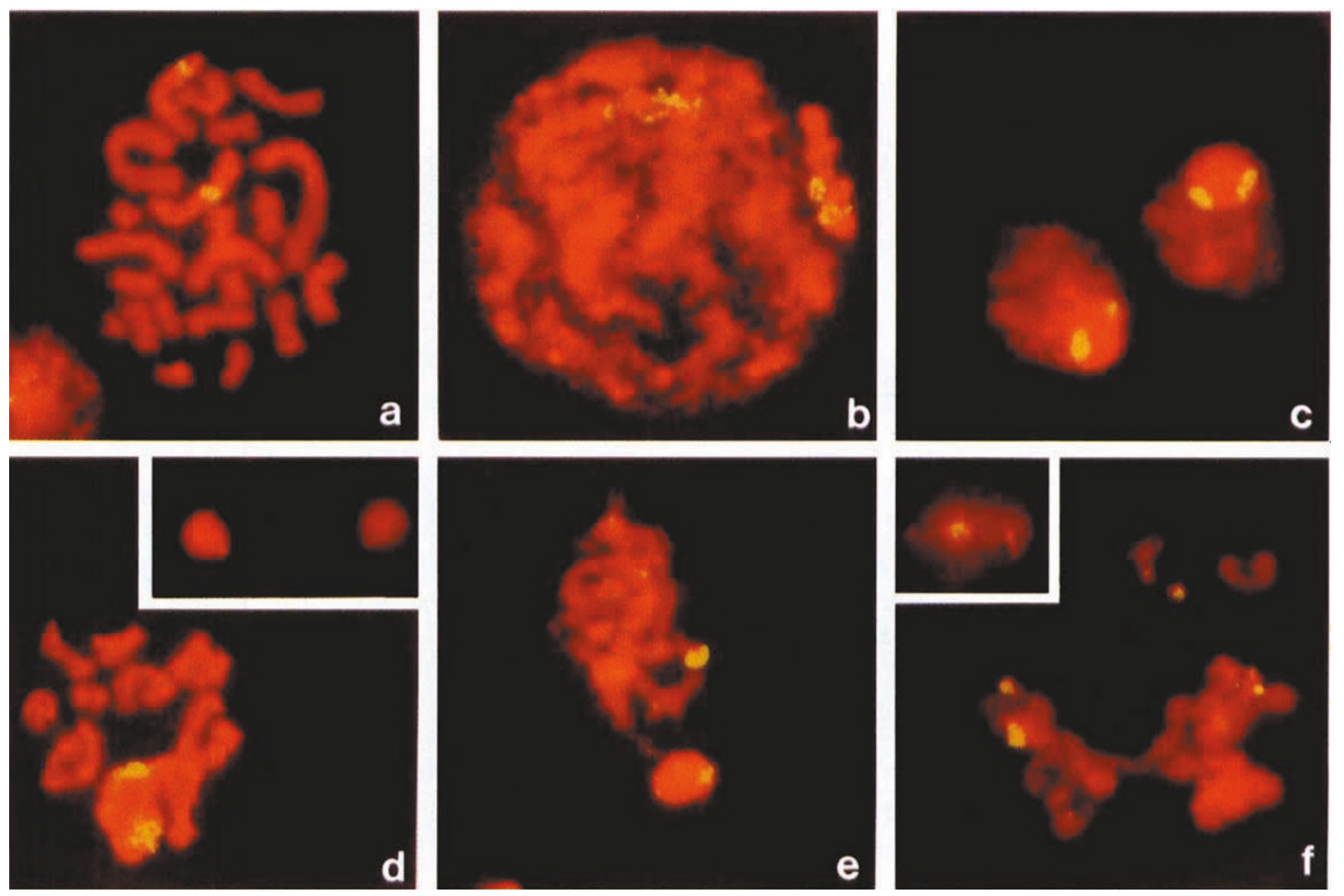

Fig. 3 Fluorescence in situ hybridization of tiger beetle nuclei with the ribosomal probe pDm238. (a) Cicindela melancholica, mitotic metaphase showing two chromosomes with hybridization signal. (b) C. melancholica, diffuse stage showing two signals. (c) C. melancholica, two zygotene nuclei showing the sex vesicle with two signals. (d) C. melancholica, metaphase I with the hybridization signal in the sex quadrivalent; inset: two spermatid nuclei with a single signal. (e) C. paludosa, pachytene with signal in one bivalent (top) and spermatid nucleus with one signal (bottom). (f) Megacephala euphratica, metaphase I with signal in three autosomal pairs; inset: spermatid nucleus with three signals of different intensity. Bar represents $5 \mu \mathrm{m}$. All $\times 2000$.

signals are also seen at zygotene and the diffuse stage (Fig. 3b,c). Hybridization of first metaphase nuclei with the probe shows that the signal clearly appears in two chromosomes of the sex quadrivalent (Fig. 3d). This is further confirmed by studying the FISH pattern of spermatids using the same probe. In this case, all spermatids show only one hybridization signal, a finding which was expected if the two hybridizing chromosomes in the quadrivalent were one $\mathrm{X}$ and the $\mathrm{Y}$ (Fig. $3 \mathrm{~d}$ inset).

FISH with the ribosomal probe in $C$. paludosa shows hybridization in one autosomal pair, and no signal is present in the single $\mathrm{X}$ chromosome. This is confirmed in spermatid nuclei, every one of which shows one signal (Fig. 3e).

In Megacephala euphratica meiotic observations show that the ribosomal cistrons are present in three medium-sized autosomal pairs but not in the $\mathrm{X}$ chromosome (Fig. 3f). Accordingly, spermatids also show three fluorescent dots (Fig. $3 \mathrm{f}$ inset). The three chromosome pairs can be distinguished by a different intensity of the signal even in spermatid nuclei.

\section{Discussion}

\section{Localization of NORs in cicindelid beetles}

Evidence from standard methods, silver staining and FISH with a ribosomal probe indicates that cicindelid beetles with multiple sex chromosomes have the NORs situated in two of these heterosomes, probably in one $\mathrm{X}$ (the largest one in $C$. melancholica, as inferred from the karyogram shown in Serrano \& Collares-Pereira, 1992) and in the $Y$ chromosome. In particular, the staining of the sex vesicle during prophase I with silver and the hybridization of this vesicle in two sites with the rDNA probe are considered as conclusive evidence for such an inference.

The two species with a male $\mathrm{X} 0$ system show a different pattern. In $C$. paludosa the results indicate that the NORs are present in one autosomal pair. Assuming that the karyotype of this species has evolved from an ancestral one with multiple sex chromosomes (Serrano et al., 1986; Galián et al., $1990)$, it must be concluded that the rDNA genes have 
been translocated from the sex chromosomes to autosomes during the evolution towards the more compact karyotype shown by this species. It not only has the heterosomes decreased in number from $\mathrm{XXY}$ to $\mathrm{X} 0$, but also the autosomes from 18 to 14 (Serrano et al., 1986).

In Megacephala euphratica three autosomal pairs have rDNA genes but the single $\mathrm{X}$ chromosome does not. The difference in intensity of the fluorescent signal between these chromosomes probably suggests that the number of copies of rDNA genes varies from one location to another. This structural difference might explain the different pattern of activity between the NORs of this species, as up to four silver precipitates only can be clearly seen during meiotic prophase.

\section{Active NORs, rDNA genes and mode of association of the multiple sex chromosomes}

As discussed above, the species of tiger beetles studied with silver staining and in situ hybridization with the ribosomal probe can be grouped into two categories: (i) species with active NORs and rDNA genes located in two of the sex chromosomes, and (ii) species with active NORs and rDNA genes in autosomal pairs but not in the single $\mathrm{X}$ chromosome. These results raise the question of the role of nucleolar material in the association and segregation of the multiple sex chromosomes in cicindelid beetles, as proposed for species of the suborder Polyphaga (John \& Lewis, 1960).

As no silver precipitate is seen after the diffuse meiotic stage of tiger beetles, it might be concluded that no nucleolar substance plays any role in the organization and segregation of the sex quadrivalent from diakinesis to the onset of anaphase I. In agreement with this conclusion no staining of any kind is found between the elements of the quadrivalent by classical staining methods; only telomeric connections are observed. Moreover, Giers (1977) clearly showed in Cicindela hybrida that if protein synthesis is experimentally inhibited with cycloheximid or puromycin, the telomeric connections between heterosomes are not developed and the quadrivalent is not formed.

It is also doubtful if the nucleolar substance plays a major role in the association of sex chromosomes during the earlier stages of meiosis. It is known that no synaptonemal complex is formed between the sex chromosomes (Giers, 1977), and only two of the heterosomes have NORs, and hence the ability to form their own nucleolus, thus making it possible to become associated through this organelle.

From these conclusions about the role of the nucleolar substance, we may expect to find some species of Cicindela with multiple sex chromosomes and NORs located only in the autosomes. Perhaps some of these species will be found among those of the subgenus Cylindera which are related to $C$. (Cylindera) paludosa.

\section{Origin and evolution of the pattern}

Serrano et al. (1986) have suggested that the occurrence of multiple sex chromosomes is an ancestral condition for the subfamily Cicindelinae. As the species discussed above belong to different lineages within the large and cosmopolitan genus Cicindela, it may be concluded that the presence of NORs on one $\mathrm{X}$ and the $\mathrm{Y}$ chromosome results from common ancestry. The relationship between this characteristic pattern and the occurrence of multiple sex chromosomes is uncertain and these might well be unrelated phenomena; that is, changes in the localization of NORs are independent of changes in the sex chromosome system. In any case, species showing a different pattern should be considered as derived, as it happens with $C$. (Cylindera) paludosa.

Interestingly, rearrangement of NORs from heterosomes to autosomes (or vice versa) has also been reported in Polyphagan beetles, namely, some dermestid beetles (John \& Shaw, 1967) and in the tenebrionids Tenebrio molitor (NORs present on Xyp) vs. Misolampus goudoti (NORs in the autosomes; Juan et al., 1993), without any change in the sex chromosome system.

The results from Megacephala euphratica (tribe Megacephalini) are consistent with the phylogenetic distance between this tribe and the Cicindelini based on karyotypic and morphological grounds. As well as the differences in number of autosomes and type of sex chromosomes (Serrano et al., 1986), M. euphratica also differs in the position and number of NORs. Further studies on members of this tribe are needed to evaluate properly the phylogenetic significance of these differences.

\section{Acknowledgements}

We are grateful to A. Andújar, J. L. Lencina, and A. S. Ortiz for their help in collecting material and Professor G. M. Hewitt who kindly made suggestions that improved the paper. This work has been supported by project DGICYT no. PB90/0357 of the Spanish Ministry of Education and Science.

\section{References}

DRETS, M. E., CORBELLA, E., PANZERA, F. AND FOLLE, G. A. 1983. $\mathrm{C}$-banding and non-homologous associations II. The 'parachute' Xyp sex bivalent and the behavior of heterochromatic segments in Epilachna paenulata. Chromosoma, 88, 249-255. 
GALIÂN, J., SERRANO, J. AND ORTIZ, A. S. 1990. Karyotypes of nine species of Cicindelini and cytotaxonomic notes on Cicindelinae (Coleoptera, Carabidae). Genetica, 82, 17-24.

GIERS, E. 1977. Die Nicht-Homologen-Assoziation multipler Geschlechtschromosomen in der Spermatogenese von Cicindela hybrida (Coleoptera). Ph.D. Thesis, University of Münster.

JOHN, B. AND LEWIS, K. R. 1960. Nucleolar controlled segregation of the sex chromosomes in beetles. Heredity, 15, 431-439.

JOHN, B. AND SHAW, D. D. 1967. Karyotype variation in Dermestid beetles. Chromosoma, 20, 371-385.

JUAN, C., PONS, J. AND PETITPIERRE, E. 1993. Localization of tandemly repeated DNA sequences in beetle chromosomes by fluorescent in situ hybridization. Chrom. Res., 1, 167-174.

POSTIGLIONI, A. AND BRUM-ZORRILLA, N. 1988. Non-relationship between nucleolus and sex chromosome system $X y_{p}$ in Chelymorpha variabilis Boheman (Coleoptera, Chrysomelidae). Genetica, 77, 137-141.

ROIHA, H., MILlER, J. R., WOODS, L. C. AND GLOVER, D. M. 1981. Arrangements and rearrangements of sequences flanking the two types of rDNA insertion in D. melanogaster. Nature, 290, 749-753.

SERrANo, A. R. M. AND Collares-PEREIRA, M. J. 1989. Cytotaxonomic study of Cephalota hispanica (Gory, 1833) and
Spiralia maura (Linnaeus, 1758), two cicindelids from Portugal (Coleoptera). Genetica, 79, 69-75.

SERrano, A. R. M. AND COllares-PEREIRA, M. J. 1992. Further analysis of the cytotaxonomy of tiger beetles (Coleoptera: Cicindelidae) from South Portugal. Nucleus, 35, 19-24.

SERRANo, J. 1980. Diferencias cariotípicas entre Cicindela maroccana pseudomaroccana y C. campestris (Col. Cicindelidae). Bol. Asoc. Esp. Entom., 4, 65-68.

SERRANO, J. 1986. A chromosome study of twenty species of Spanish carabid beetles (Coleoptera). Genetica, 69, 133-142.

SERRANO, J., GALIAN, J. AND ORTIZ, A. 1986. Cicindelid beetles without multiple sex chromosomes (Coleoptera, Caraboidea). Can. J. Genet. Cytol., 28, 235-239.

SMITH, S. G. AND VIRKKI, N. 1978. Coleoptera. In: John, B. (ed.) Animal Cytogenetics, vol. 3, Insecta 5. Gebrüder Borntraeger, Berlin, Stuttgart.

VIRKKI, N., MAZZELLA, C. AND DENTON, A. 1990. Staining of substances adjacent to the sex bivalent in certain weevils of Puerto Rico. J. Agric. Univ. P.R., 74, 405-418.

VIRKKI, N., MAZZELLA, C. AND DENTON, A. 1991. Silver staining of the Coleoptera $\mathrm{Xy}_{\mathrm{p}}$ sex bivalent. Cytobios, 67, 45-63.

WEBER, F. 1971. Korrelierte Formveränderrungen von Nukleolus und nukleolusassozüertem Heterochromatin bei der Gattung Carabus (Coleoptera). Chromosoma, 34, 261-273. 